\title{
Analysis of the Crystallization of Mold Flux for Continuous Casting of Steel
}

\author{
Hidenori MIZUNO, Hisao ESAKA, Kei SHINOZUKA and Manabu TAMURA \\ Department of Materials Science and Engineering, National Defense Academy, 1-10-20 Hashirimizu Yokosuka, Kanagawa 239- \\ 8686 Japan.
}

(Received on August 6, 2007; accepted on November 7, 2007)

\begin{abstract}
In continuous casting of steel, mold fluxes are used to prevent surface defects, such as longitudinal cracks. The crystallization of mold flux promotes mild cooling of the steel shell, but crystallization behavior has been still uncertain. Therefore, this study has been carried out to analyze the crystallization processes of mold flux. Mold flux used in this study has high tendency for crystallization. Quenched specimens were heat-treated in various conditions and characterized. Glassy specimen heat-treated in the electric furnace over $550^{\circ} \mathrm{C}$ for $180 \mathrm{~min}$ crystallized. These crystalline were confirmed to be cuspidine by XRD analysis. The number of grains decreased and the average grain size increased with rise of temperature of heat treatment. The growth velocity also increased with rise of temperature.

In-situ observation by the laser microscope revealed that the glassy specimen crystallized in a moment over $600^{\circ} \mathrm{C}$ and the surface of the specimen turned to be rough. This may lead to mild cooling in the mold.

KEY WORDS: mold flux; crystallization; heat treatment; continuous casting; cuspidine; nucleation; X-ray; laser microscope.
\end{abstract}

\section{Introduction}

In continuous casting of steel, mold fluxes are used for various reasons. ${ }^{1)}$ They are: (1) Insulation the molten steel, (2) Prevention of molten steel from oxidation, (3) Absorption of inclusions floating in the mold, (4) Lubrication between the solidified shell and mold, (5) Control the heat transfer. They play very important roles in the mold of continuous casting of steel.

In these days, it is desired to increase the casting velocity to raise the productivity of steel. For middle carbon steels, or hypo-peritectic steels, it is difficult to increase the casting velocity because of high sensitivity of longitudinal surface cracking. ${ }^{2)}$ Thus, the maximum casting velocity of these steel grades is lower than that of low carbon steel. It has been recognized that longitudinal cracking is caused by uneven solidification of the steel. ${ }^{3-6)}$ To suppress the uneven solidification in the mold, various attempts to decrease the heat flux in the mold have been made. ${ }^{7-10)}$ One of the available attempts has been improvement of mold flux. ${ }^{9,10)}$ Crystallization of mold flux in the mold leads to mild cooling of solidified shell. Two major mechanisms have been proposed for mild cooling. Firstly, the interfacial thermal resistance between the mold and the crystalline layer of mold flux controls the total heat transfer in the mold. ${ }^{11,12)}$ Secondly, the radiation heat flux decreases in the crystalline phase. This controls the total heat flux in the mold. ${ }^{13,14)}$ However, the mechanism of mild cooling is still uncertain.

Anyway, it is clear that crystallization of mold flux reduces the heat transfer. There may be two paths for crystal- lization of mold flux. The first one may be that mold flux directly crystallizes from molten state. The second one may be that mold flux crystallizes via glassy state, which is initially quenched from molten state. Initial solidification of steel is influenced by the behavior of mold flux and therefore, it is important to understand the crystallization process of mold flux. Thus, in order to understand the crystallization process via glassy state, some pieces of quenched mold fluxes have been heat-treated in various conditions.

\section{Experimental Procedure}

\subsection{Preparation of Raw Materials}

In this work, an actual mold flux for continuous casting of steel, which is relatively easier to crystallize, was used. Tables 1 and $\mathbf{2}$ show the properties and composition of this mold flux, respectively. The mold flux was previously decarburized in the air at about $800^{\circ} \mathrm{C}$ and then the mold flux was melted in the graphite crucible at $1350^{\circ} \mathrm{C}$ for $20 \mathrm{~min}$ in the air. Then the molten flux was poured on a graphite plate and then pressed by another graphite plate to obtain the quenched specimens. The thickness of specimens was about $1 \mathrm{~mm}$.

\subsection{Heat Treatment}

\subsubsection{Heat Treatment in an Electric Furnace}

The quenched specimens were put in the alumina crucible and were heat-treated at various temperatures for $180 \mathrm{~min}$ in the air using the electric furnace. The tempera- 
Table 1. Properties of mold flux used in this study.

\begin{tabular}{|c|c|c|c|}
\hline $\begin{array}{c}\text { Melting } \\
\text { temperature } \\
\left({ }^{\circ} \mathrm{C}\right)\end{array}$ & $\begin{array}{c}\text { Solidification } \\
\text { temperature } \\
\left({ }^{\circ} \mathrm{C}\right)\end{array}$ & $\begin{array}{c}\text { Viscosity } \\
\text { at } 1300^{\circ} \mathrm{C} \\
\text { (poise) }\end{array}$ & $\mathrm{CaO} / \mathrm{SiO}_{2}$ \\
\hline 1140 & 1180 & 1.3 & 1.2 \\
\hline
\end{tabular}

Table 2. Chemical composition of mold flux used in this study.

\begin{tabular}{|c|c|c|c|c|c|}
\hline \multicolumn{6}{|c|}{ Chemical composition (mass\%) } \\
\hline $\mathrm{SiO}_{2}$ & $\mathrm{Al}_{2} \mathrm{O}_{3}$ & $\mathrm{CaO}$ & $\mathrm{Na}_{2} \mathrm{O}$ & $\mathrm{F}$ & $\mathrm{MgO}$ \\
\hline 32 & 2.6 & 39 & 10 & 7 & 5.8 \\
\hline
\end{tabular}

ture range was from 500 to $900^{\circ} \mathrm{C}$. After heat treatment, each specimen was cut into two pieces. Half of them was molded in the polyester resin and was polished by water proof paper and by alumina slurry. Then it was etched with saturated picric acid for a few seconds and the structure was observed by an optical microscope. The other half was crushed into powder for XRD analysis.

Furthermore, in order to analyze the change of structure with time, the interruption tests were carried out at some temperatures of heat treatment.

\subsubsection{In-situ Observation by a Laser Microscope}

The surfaces of quenched specimens were polished by water proof paper and by alumina slurry. After that, the size of specimen was adjusted so as to be put in an alumina crucible for a laser microscope. The inner diameter of the crucible was $5 \mathrm{~mm}$. Then the specimen was heated in an infrared image furnace in argon atmosphere and directly observed by a laser confocal microscope. The specimens were heat-treated at various temperatures for $20 \mathrm{~min}$. The temperature range was from 600 to $900^{\circ} \mathrm{C}$. The heating rate was set to be $500^{\circ} \mathrm{C} / \mathrm{min}$. R-type thermocouple was attached to the sample holder to control the temperature. During the experiments, the events that took place on the surface were observed and were recorded by a DVD recorder.

\section{Experimental Results}

\subsection{Characterization of Raw Materials}

In order to characterize the raw materials in this study, the quenched specimens were analyzed by XRD. One of the results is shown in Fig. 1. There was no specific peak in XRD profile. The broad peak appeared from $20^{\circ}$ and $30^{\circ}$ was due to the sample holder which was made of Pyrex glass. The quenched specimens were confirmed to be glassy state.

\subsection{Heat Treatment with Electric Furnace}

\subsubsection{XRD Analysis}

The XRD profile of the specimen which was heat-treated at $520^{\circ} \mathrm{C}$ for $180 \mathrm{~min}$ is shown in Fig. 2. In this case, no specific peak was identified and was the same as that shown in Fig. 1.

The XRD profile of the specimen which was heat-treated

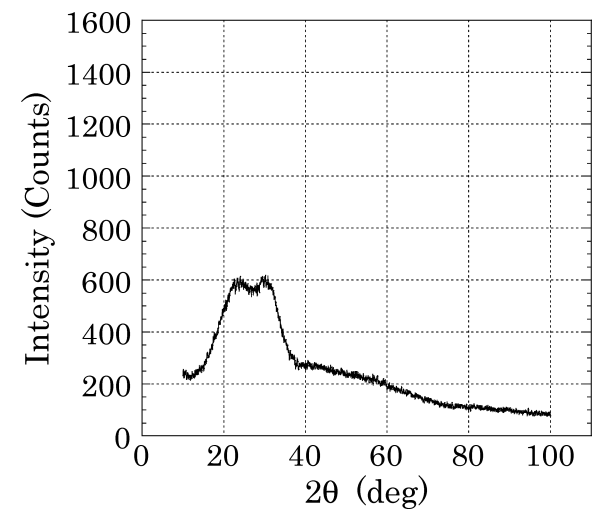

Fig. 1. XRD profiles of quenched glassy specimen.

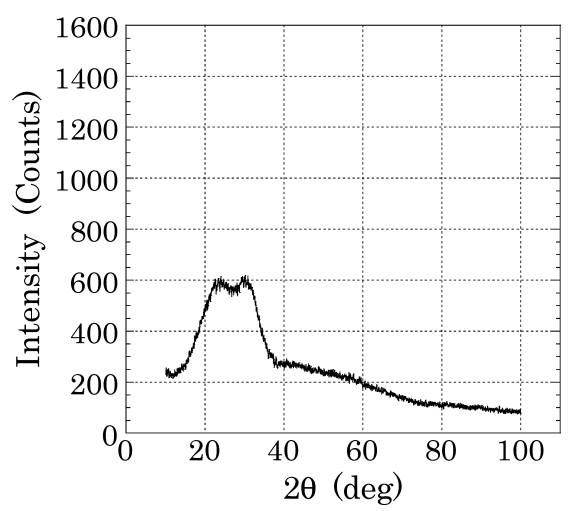

Fig. 2. XRD profiles of the specimen heat-treated at $520^{\circ} \mathrm{C}$ for $180 \mathrm{~min}$.

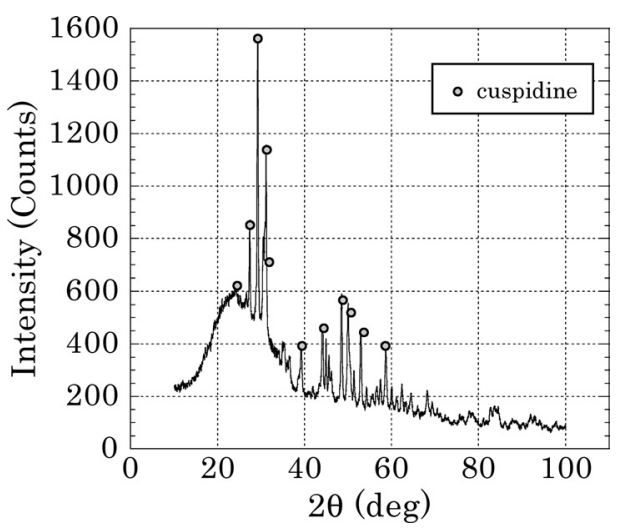

Fig. 3. XRD profiles of specimen heat-treated at $650^{\circ} \mathrm{C}$ for $180 \mathrm{~min}$.

at $650^{\circ} \mathrm{C}$ for $180 \mathrm{~min}$ is shown in Fig. 3. In this case, so many sharp peaks were recognized and it was found that these peaks corresponded to cuspidine $\left(3 \mathrm{CaO} \cdot 2 \mathrm{SiO}_{2}\right.$. $\mathrm{CaF}_{2}$ ).

The specimens heat-treated at $500^{\circ} \mathrm{C}$ and $520^{\circ} \mathrm{C}$ for $180 \mathrm{~min}$ remained glassy. However, the specimens heattreated at other temperature range (over $550^{\circ} \mathrm{C}$ ) crystallized to cuspidine, though there were some differences in peak height in XRD profiles.

\subsubsection{Analysis of Microstructure}

The microstructures of the cross section of specimens, which were heat-treated at relatively high temperature for 180 min, are shown in Fig. 4. One can recognize that the specimens were composed by many grains. In case of heat- 


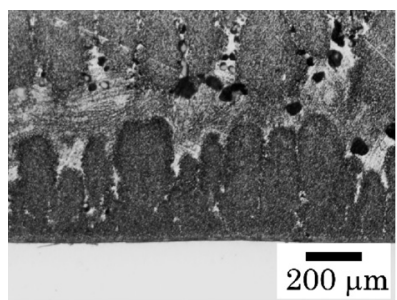

(a) $800^{\circ} \mathrm{C}-180 \mathrm{~min}$

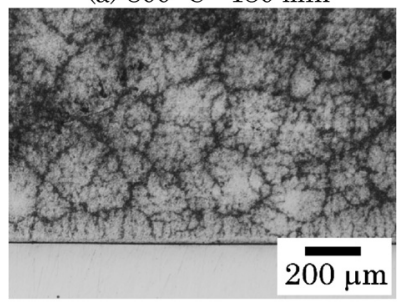

(c) $700{ }^{\circ} \mathrm{C}-180 \mathrm{~min}$

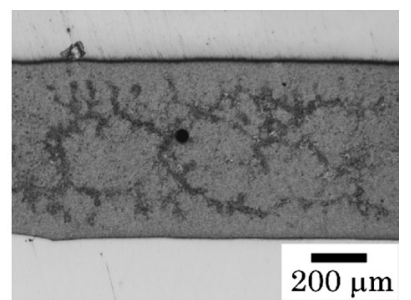

(b) $750{ }^{\circ} \mathrm{C}-180 \mathrm{~min}$
Fig. 4. Comparison of grain structure after heat-treated for $180 \mathrm{~min}$ in the electric furnace observed by the optical microscope.

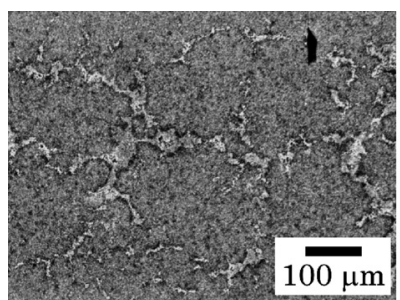

(a) $750{ }^{\circ} \mathrm{C}-180 \mathrm{~min}$

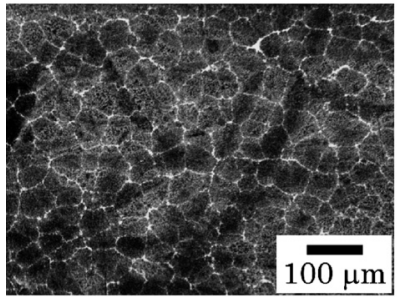

(c) $650{ }^{\circ} \mathrm{C}-180 \mathrm{~min}$

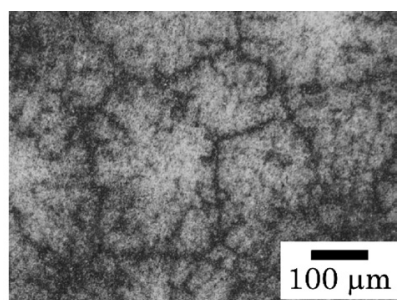

(b) $700{ }^{\circ} \mathrm{C}-180 \mathrm{~min}$

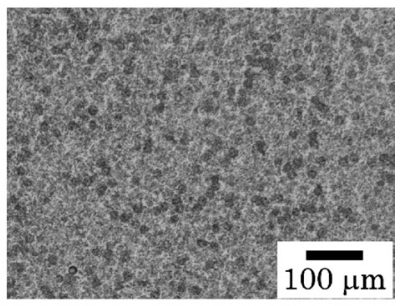

(d) $600^{\circ} \mathrm{C}-180 \mathrm{~min}$
Fig. 5. Comparison of grain structure after heat-treated for $180 \mathrm{~min}$ in the electric furnace observed by the optical microscope.

treated at $800^{\circ} \mathrm{C}$ (Fig. 4(a)), columnar grains were observed. These grains might grow from the surface of the specimen. On the other hand, in case of heat-treated at $700^{\circ} \mathrm{C}$ (Fig. 4(c)), only equiaxed grains were observed. The aspect ratio of these grains is almost unity and it is hardly recognized to grow in the specific direction. In case of $750^{\circ} \mathrm{C}$, columnar grains as well as equiaxed grains were observed (Fig. 4(b)). It was found that equiaxed grains were observed at relatively low temperature of heat treatment.

In order to compare the size of equiaxed grains, the microstructures of the specimens heat-treated at relatively low temperatures for $180 \mathrm{~min}$ have been analyzed. These results are shown in Fig. 5. It was found that the equiaxed grain size increased with rise of temperature of heat treatment.

In order to analyze the change in equiaxed grain size with time, the interruption tests have been carried out at $650^{\circ} \mathrm{C}$ and $800^{\circ} \mathrm{C}$. Figure 6 shows the changes in microstructure of the specimens heat-treated at $650^{\circ} \mathrm{C}$ for various heat treatment times. In case of 15 min (Fig. 6(a)), no grain structure was recognized by the optical microscope.

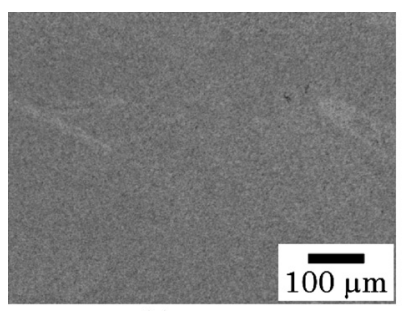

(a) $15 \mathrm{~min}$

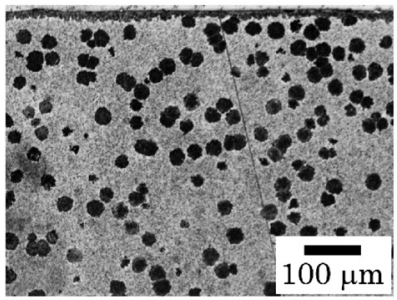

(c) $60 \mathrm{~min}$

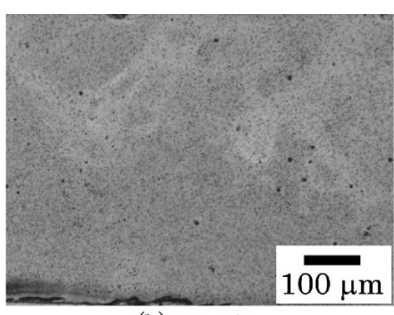

(b) $30 \mathrm{~min}$

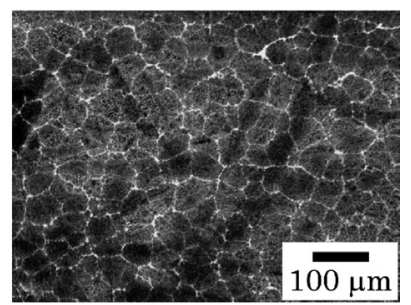

(d) $180 \mathrm{~min}$
Fig. 6. Experimental results of interruption tests. Cross section of mold flux heat-treated at $650^{\circ} \mathrm{C}$ in the electric furnace observed by the optical microscope.

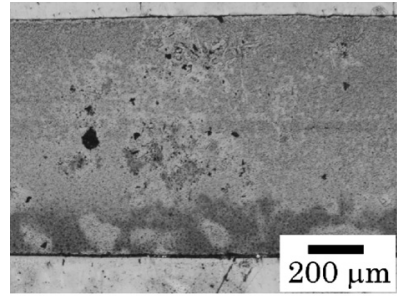

(a) $5 \mathrm{~min}$

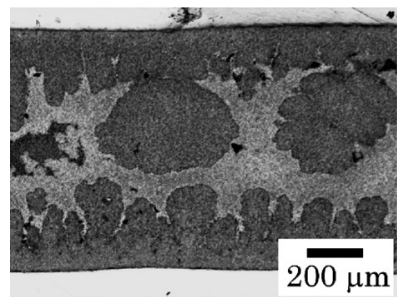

(c) $60 \mathrm{~min}$

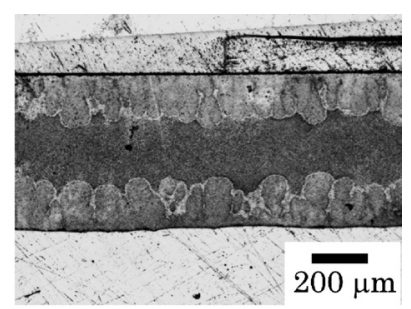

(b) $30 \mathrm{~min}$

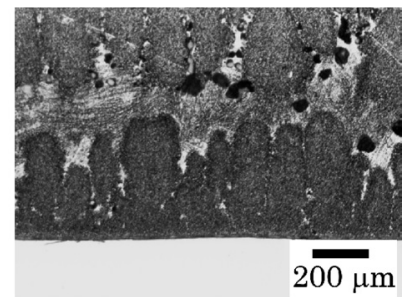

(d) $180 \mathrm{~min}$
Fig. 7. Experimental results of interruption tests. Cross section of mold flux heat-treated at $800^{\circ} \mathrm{C}$ in the electric furnace observed by the optical microscope.

At $30 \mathrm{~min}$ (Fig. 6(b)), many but quite fine grains were observed. Further, at $60 \mathrm{~min}$ (Fig. 6(c)), many grains were recognized. Not only the number of grains but also grain size increased, comparing the microstructure at $30 \mathrm{~min}$. At $180 \mathrm{~min}$ (Fig. 6(d)), the grain size increased and the cross section of the specimen was completely covered with grains. In case of heat treatment at $15 \mathrm{~min}$, cuspidine was identified by XRD analysis, though no grain was recognized by the optical microscope. The XRD profiles of the specimen, the grain structure of which were shown in Fig. 6 , were almost the same and only cuspidine was recognized as crystalline. Figure 7 shows the changes in microstructure of the specimens heat-treated at $800^{\circ} \mathrm{C}$ for various heat treatment times. In case of $5 \mathrm{~min}$ (Fig. 7(a)), no grain was observed. At $30 \mathrm{~min}$ (Fig. 7(b)), columnar grains were observed near the surface. At $60 \mathrm{~min}$ (Fig. 7(c)), columnar grains grew toward the center of the specimen and some equiaxed grains were also observed. In case of $180 \mathrm{~min}$, columnar grains which grew more were observed. 


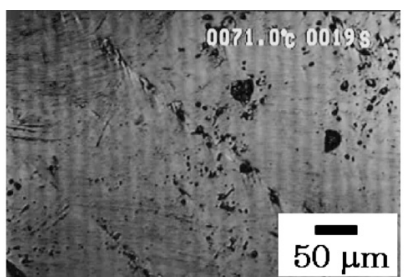

(a) $t=19 \mathrm{~s} T=71^{\circ} \mathrm{C}$

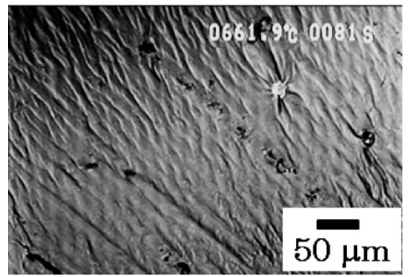

(c) $t=81 \mathrm{~s} T=662{ }^{\circ} \mathrm{C}$

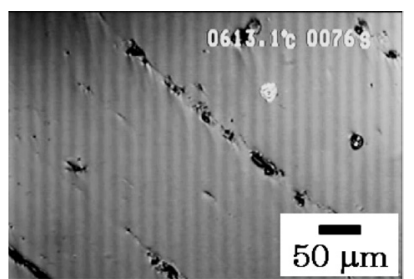

(b) $t=76 \mathrm{~s} T=613^{\circ} \mathrm{C}$

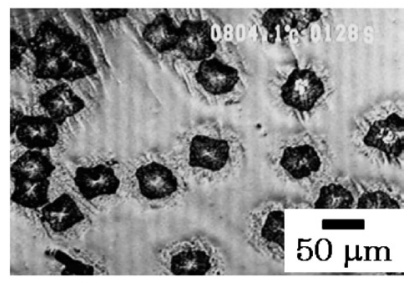

(d) $t=128 \mathrm{~s} T=804^{\circ} \mathrm{C}$
Fig. 8. Morphological change on the surface during heating from room temperature to $800^{\circ} \mathrm{C}$ observed by the laser microscope (Heating rate was $500^{\circ} \mathrm{C} / \mathrm{min}$ ).

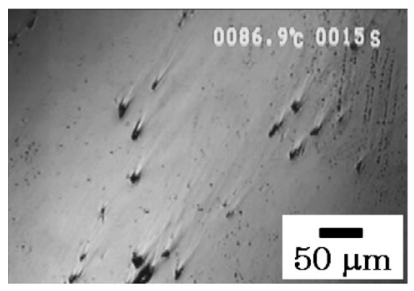

(a) $t=15 \mathrm{~s} T=87^{\circ} \mathrm{C}$

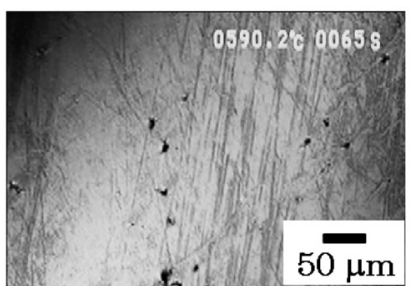

(c) $t=65 \mathrm{~s} T=590{ }^{\circ} \mathrm{C}$

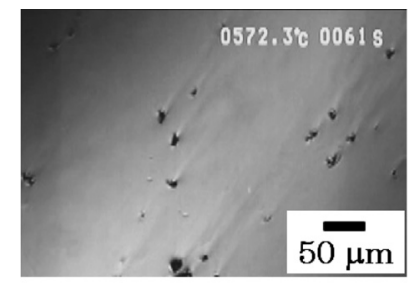

(b) $t=61 \mathrm{~s} T=572^{\circ} \mathrm{C}$

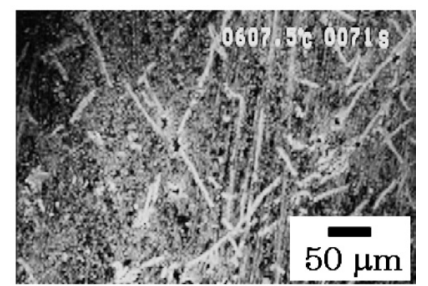

(d) $t=71 \mathrm{~s} T=608^{\circ} \mathrm{C}$
Fig. 9. Morphological change on the surface during heating from room temperature to $600^{\circ} \mathrm{C}$ observed by the laser microscope (Heating rate was $500^{\circ} \mathrm{C} / \mathrm{min}$ ).

\subsection{Experimental Results of In-situ Observation}

3.3.1. Morphological Change during Heating

Here the experimental results on $800^{\circ} \mathrm{C}$ and $600^{\circ} \mathrm{C}$ are presented as examples.

The morphological changes on the surface during heating from room temperature to $800^{\circ} \mathrm{C}$ are shown in Fig. 8 . At $71^{\circ} \mathrm{C}$ (Fig. $8(\mathrm{a})$ ), no change was observed. At $613^{\circ} \mathrm{C}$ (Fig. 8(b)), the surface became smooth. At $662^{\circ} \mathrm{C}$ (Fig. $8(\mathrm{c}))$, the smooth surface turned to be rough in a moment. Many tiny waves were observed on the surface. At $804^{\circ} \mathrm{C}$ (Fig. 8(d)), this was almost the same moment to reach the aimed temperature, many black rounded particles suddenly emerged on the surface.

The morphological changes on the surface during heating from room temperature to $600^{\circ} \mathrm{C}$ are shown in Fig. 9. At $87^{\circ} \mathrm{C}$ (Fig. 9(a)), no change was observed. At around $572^{\circ} \mathrm{C}$ (Fig. 9(b)), the surface became smooth. At $590^{\circ} \mathrm{C}$ (Fig. 9(c)), the surface turned to be rough in a moment. However the wavy pattern was weaker than that indicated in Fig. 8(c). Then, at $608^{\circ} \mathrm{C}$ (Fig. 9(d)), many small grains abruptly precipitated on the surface. This was almost the

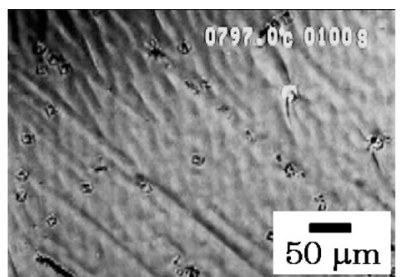

(a) $t=100 \mathrm{~s} T=797^{\circ} \mathrm{C}$

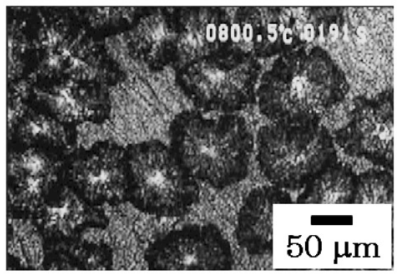

(c) $t=191 \mathrm{~s} T=801^{\circ} \mathrm{C}$

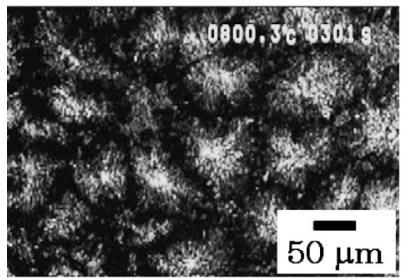

(e) $t=301 \mathrm{~s} T=800^{\circ} \mathrm{C}$
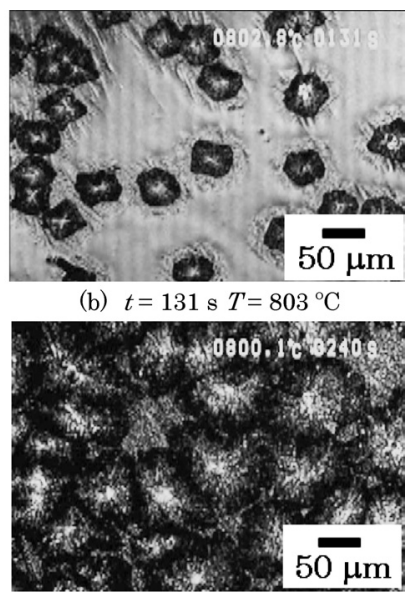

(d) $t=240 \mathrm{~s} T=800{ }^{\circ} \mathrm{C}$ (b) $t=131 \mathrm{~s} T=803^{\circ} \mathrm{C}$

Fig. 10. Morphological change on the surface during holding at $800^{\circ} \mathrm{C}$ observed by the laser microscope. This time includes the heating time from room temperature to $800^{\circ} \mathrm{C}$.

same moment to reach the aimed temperature.

\subsubsection{Morphological Change during Holding}

Here again, the experimental results on $800^{\circ} \mathrm{C}$ and $600^{\circ} \mathrm{C}$ are presented as examples. The time, when the heating was started, was defined to be $t=0$.

The morphological changes on the surface during holding at $800^{\circ} \mathrm{C}$ are shown in Fig. 10. At $t=100 \mathrm{~s}$ (Fig. 10(a)), the grains started to be observed. These grains grew as shown in Figs. 10(b) and 10(c). At $t=240 \mathrm{~s}$ (Fig. 10(d)), the surface was almost covered with grains. Further, at $t=301 \mathrm{~s}$ (Fig. 10(e)), the morphology on the surface was almost the same as that at $240 \mathrm{~s}$.

The morphological changes on the surface during holding at $600^{\circ} \mathrm{C}$ are shown in Fig. 11. At $t=65 \mathrm{~s}$ (Fig. 11(a)), it was just before reaching the aimed temperature, no grain was observed. At $t=70 \mathrm{~s}$ (Fig. 11(b)), it was almost the same moment to reach the aimed temperature, many grains immediately precipitated on the surface and filled the surface. As shown in Figs. 11(c) and 11(d), the grains grew and grain boundaries became clear. At $t=800 \mathrm{~s}$ (Fig. 11(e)), the morphology on the surface was almost the same as that at $600 \mathrm{~s}$.

\section{Discussions}

\subsection{Characterization of Crystallization}

The XRD analysis of the quenched specimens has been performed. As shown in Fig. 1, there was no specific peak in the XRD profile. Therefore, it can be concluded that the quenched specimens were available for the study of crystallization via glassy state by heat treatment.

Almost all specimens which were heat-treated for 


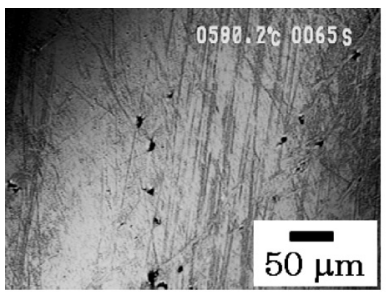

(a) $t=65 \mathrm{~s} T=590^{\circ} \mathrm{C}$

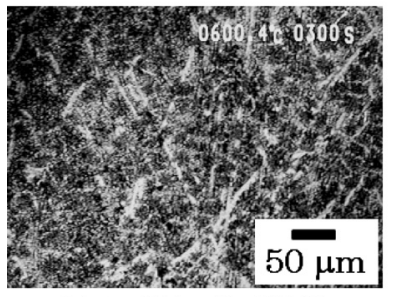

(c) $t=300 \mathrm{~s} T=600^{\circ} \mathrm{C}$

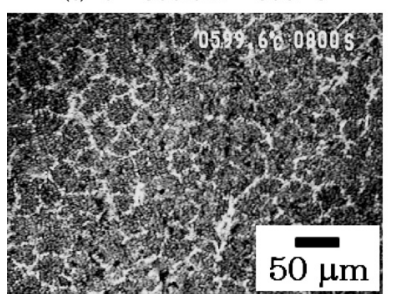

(e) $t=800 \mathrm{~s} T=600^{\circ} \mathrm{C}$

Fig. 11. Morphological change on the surface during holding at $600^{\circ} \mathrm{C}$ observed by the laser microscope. This time includes the heating time from room temperature to $600^{\circ} \mathrm{C}$.

180 min crystallized and the species of crystalline was cuspidine. However, the specimens, which were heat-treated at $500^{\circ} \mathrm{C}$ and $520^{\circ} \mathrm{C}$ for $180 \mathrm{~min}$, did not crystallize as shown in Fig. 2. This indicates that the specimens heat-treated under these conditions were still in glassy state and therefore it is supposed that the specimens were still in the incubation period for crystallization.

\subsection{Morphology of Grains}

As shown in Figs. 4 and 7, the columnar grains seem to grow unidirectionally from surface to center of the specimen. Further, the equiaxed grains seem to grow radially as shown in Figs. 4, 5, 10 and 11.

In order to clarify the morphology of grain during heat treatment, the thin samples for polarizing microscope have been prepared and observations with polarizing microscope have been made. One example of these observations of columnar grains is shown in Fig. 12. This specimen was heat-treated at $800^{\circ} \mathrm{C}$ for $180 \mathrm{~min}$. Here typical dendritic patterns were clearly observed and this indicated that the grain precipitated on the surface grew towards the center of the specimen.

The equiaxed grains observed with the laser microscope were analyzed by the FE-SEM. One example of these observations is shown in Fig. 13. This specimen was heattreated at $600^{\circ} \mathrm{C}$ for $20 \mathrm{~min}$ and corresponded to the specimen shown in Fig. 11. The grain exhibited the typical dendritic pattern. The diameter of the grain was approximately $20 \mu \mathrm{m}$ and this agreed with the observation results shown in Figs. 11(d) and 11(e).

In short, it is certain that grains on the surface and in the specimen exhibited the dendritic pattern. Since the under-

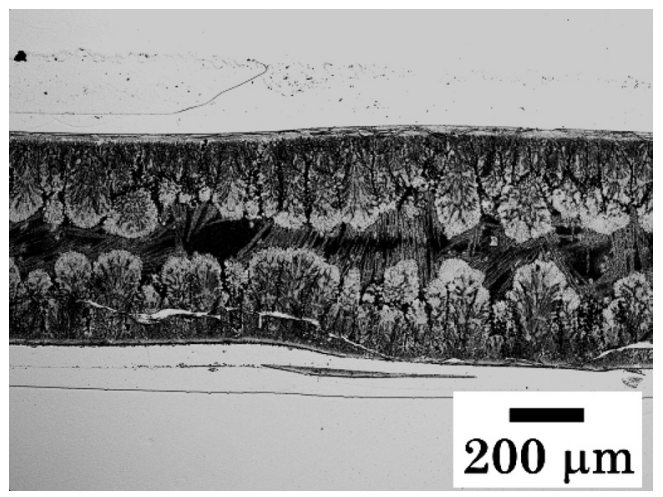

Fig. 12. Cross section of mold flux heat-treated at $800^{\circ} \mathrm{C}$ in the furnace observed by the polarizing microscope.

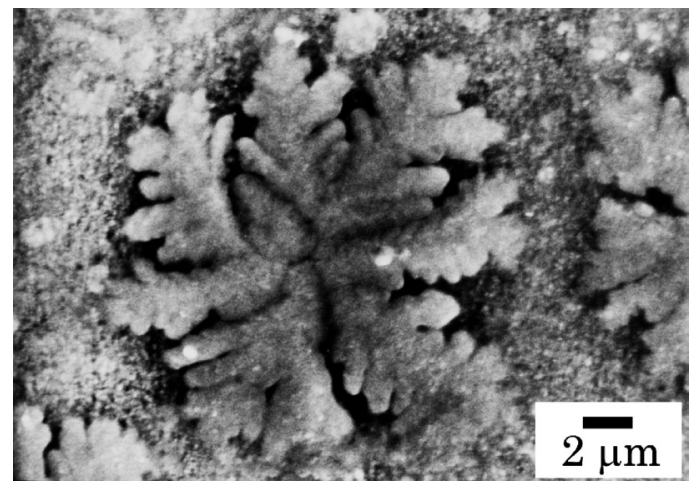

Fig. 13. The grain precipitated on the surface holding at $600^{\circ} \mathrm{C}$ for $20 \mathrm{~min}$ in the infrared furnace observed by the FESEM.

cooling for grain growth is necessary for dendritic growth of metals, ${ }^{15)}$ these grains which exhibited the typical dendritic patterns grew with large undercooling.

\subsection{Number and Growth Rate of Grains}

In order to analyze the crystallization process from the glassy state, the number of grains and growth velocity of grains were characterized in heat treatment. Furthermore, the relation between number and growth velocity of grains as a function of temperature were discussed.

\subsubsection{Number of grains}

(1) Number of Grains as a Function of Time

The changes in grain morphologies which were heattreated at $650^{\circ} \mathrm{C}$ for various times was shown in Fig. 6 . The number of grains as a function of time was evaluated. Here, the number of grains per unit area, which is equal to density of grains $\left(\rho_{\text {grain }}\right)$ was characterized. The result is shown in Fig. 14. Since these were the results of interruption tests, there were some scatters in these results. However, it can be concluded that $\rho_{\text {grain }}$ increased abruptly and after that it was almost constant during heat treatment.

Based on the experimental results of in-situ observation shown in Fig. 10, the change in $\rho_{\text {grain }}$ with heat treatment time was analyzed. In this case, the temperature of heat treatment was $800^{\circ} \mathrm{C}$. The result is shown in Fig. 15. $\rho_{\text {grain }}$ rapidly increased in the initial stage and then gradually increased during heat treatment. Therefore, it can be safely concluded that the generation of grain took place in a moment and $\rho_{\text {grain }}$ did not increase much during heat treat- 


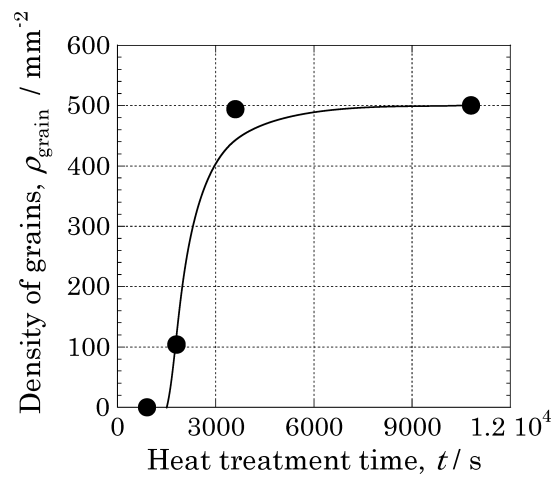

Fig. 14. Relation between heat treatment time and density of grains obtained by the interruption tests. The specimen was heat-treated with electric furnace at $650^{\circ} \mathrm{C}$.

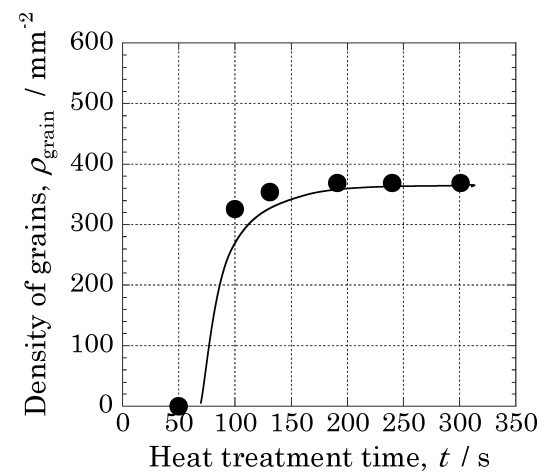

Fig. 15. Relation between heat treatment time and density of grains obtained by in-situ observation. The specimen was heat-treated with infrared furnace at $800^{\circ} \mathrm{C}$.

ment. This finding holds true in other conditions of heat treatment within the range of this study.

(2) Number of Grains as a Function of Temperature

As shown in Figs. 14 and 15, the numbers of grains at certain temperatures of heat treatment were almost constant during heat treatment, or in final stage of heat treatment. Similarly, $\rho_{\text {grain }}$ at another temperature of heat treatment have been analyzed. The relation between temperature of heat treatment and $\rho_{\text {grain }}$ is shown in Fig. 16. Here, all experimental data obtained in this study are included. The absolute values of $\rho_{\text {grain }}$ were not equal each other even in the same temperature of heat treatment. There may be following three reasons. They are: the difference of furnace, the difference of diffusion of atoms or ions (bulk or surface) and the difference of location for observation. However, it was found that $\rho_{\text {grain }}$ decreased with rise of temperature of heat treatment. The reason of this will be discussed in the following Sec. 4.3.3.

\subsubsection{Size of Grains}

(1) Size of Grains as a Function of Temperature of Heat Treatment

The cross sections of the specimens, which were heattreated at various temperatures for $180 \mathrm{~min}$, are shown in Fig. 5. Almost all grains found in Fig. 5 were spherical and then the average diameters of grains were evaluated. The results of in-situ observation by the laser microscope are shown in Figs. 10 and 11. The grains on the surface were also spherical and the average diameters of grains were

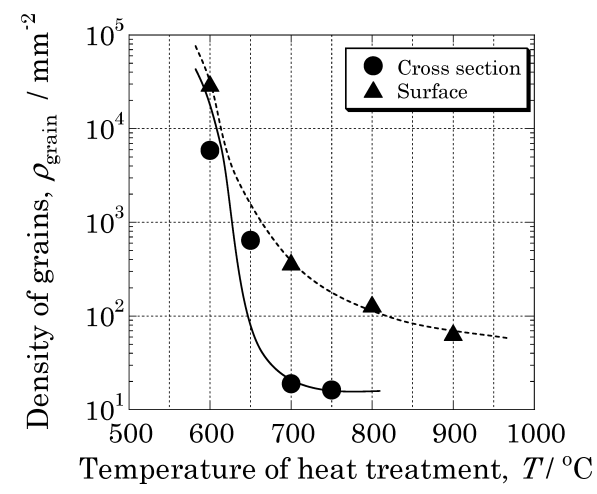

Fig. 16. Relation between temperature of heat treatment and density of grains.

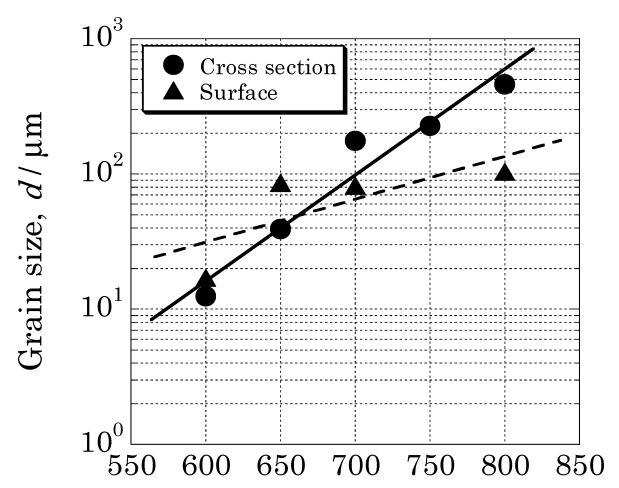

Temperature of heat treatment, $T /{ }^{\circ} \mathrm{C}$

Fig. 17. Relation between temperature of heat treatment and grain size heat-treated for $180 \mathrm{~min}$.

evaluated. The relation between temperature of heat treatment and average grain size is shown in Fig. 17. The average grain size increased with rise of temperatures of heat treatment in the range of this study. This is attributed to the coupled effect of nucleation rate and growth velocity as a function of temperature, which will be discussed in Sec. 4.3.3.

(2) Size of Grains as a Function of Heat Treatment Time and Growth Velocity of Grains

From the interruption tests of heat treatment in the electric furnace, the morphologies of cross section were obtained as shown in Fig. 7. The average diameters of grains were evaluated and the relation between heat treatment time and average diameter of grain was indicated in Fig. 18. There were some scatters in the experimental results because of interruption test. However, it can be said that the grains grew at a constant velocity by approximately $5000 \mathrm{~s}$ and after that the grain diameter did not increase much, because the grains touched to another grains. Here the growth velocity of grains ( $\left.V_{\text {grain }}\right)$ was obtained to be $1.3 \times$ $10^{-2} \mu \mathrm{m} / \mathrm{s}$.

Based on the experimental results of in-situ observation as shown in Fig. 10, the change of average diameter of grains in heat treatment time is shown in Fig. 19. Here again, the grain diameter increased linearly in the initial stage and the slope became gentle gradually. Finally, the grain size became a constant value, approximately $120 \mu \mathrm{m}$. The growth velocity of grain $\left(V_{\text {grain }}\right)$ was obtained from the slope indicated by solid line in Fig. $19 . V_{\text {grain }}$ at $800^{\circ} \mathrm{C}$ was 


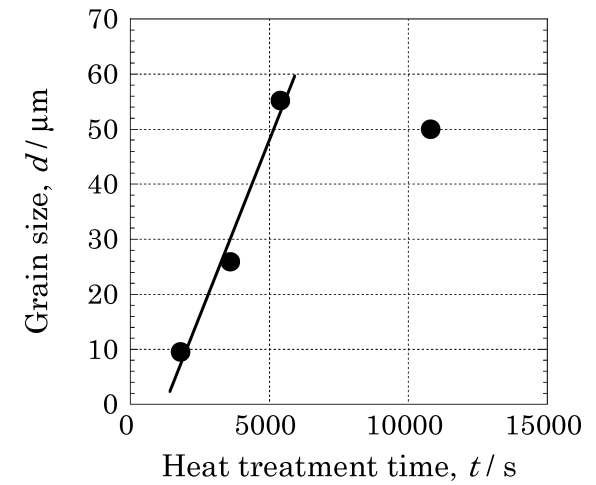

Fig. 18. Relation between heat treatment time and grain size at $650^{\circ} \mathrm{C}$ obtained by interruption tests using electric furnace.

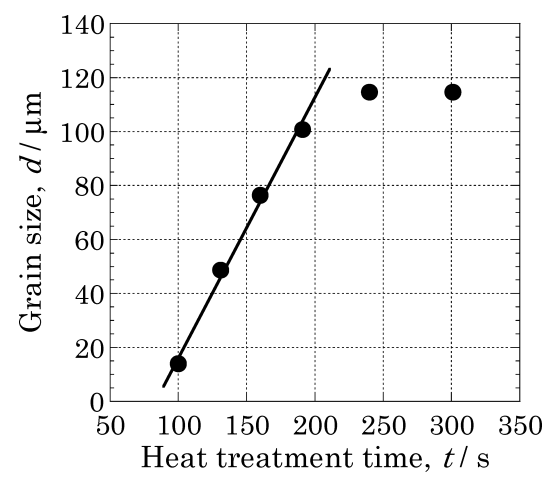

Fig. 19. Relation between heat treatment time and grain size at $800^{\circ} \mathrm{C}$ obtained by in-situ observation. This heat treatment time includes the heating time from room temperature to $800^{\circ} \mathrm{C}$.

determined to be $0.95 \mu \mathrm{m} / \mathrm{s}$.

When the temperature of heat treatment was low, the grains were small as shown in Fig. 11. It was impossible to directly measure the change of grain size with time. Therefore, in this case following two methods were adopted to measure the grains size.

Firstly, a certain grain, that generated after many grain grew, was used to measure the size as a function of time with enlarged view. Morphological changes with time are shown in Fig. 20. The grain paid attention was indicated by a white open circle. The experimental result is shown in Fig. 21. The grain linearly increased its size from $140 \mathrm{~s}$ to $320 \mathrm{~s}$. After that, the grain size increased slowly because it came into contact with the neighboring grains. $V_{\text {grain }}$ was obtained from the slope in the initial stage of this figure and was $2.9 \times 10^{-2} \mu \mathrm{m} / \mathrm{s}$.

Secondly, the growth velocity of grain was estimated without characterizing the change of grain size with time. According to the in-situ observation, many grains generated at $t=70 \mathrm{~s}$ in a moment as shown in Fig. 11(b). But it was not possible to evaluate the grain size at that time. Thus, the grain diameter at $t=70 \mathrm{~s}$ was assumed to be $0 \mu \mathrm{m}$. In contrast to this, at $t=600 \mathrm{~s}$, the shape of grains was clearly recognized and the average grain size was also evaluated. Assuming that the growth velocity was constant from $t=70 \mathrm{~s}$ to $t=600 \mathrm{~s}, V_{\text {grain }}$ was obtained to be $4.1 \times 10^{-2} \mu \mathrm{m} / \mathrm{s}$. This value is close to the estimated value from Fig. 21, $2.9 \times 10^{-2} \mu \mathrm{m} / \mathrm{s}$.

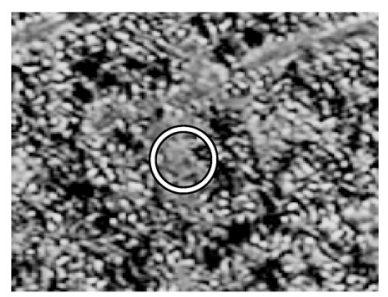

(a) $t=140 \mathrm{~s}$

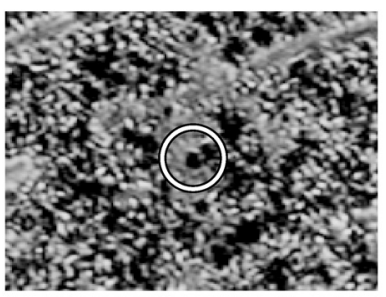

(c) $t=260 \mathrm{~s}$

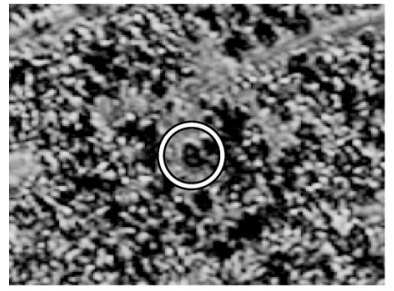

(e) $t=500 \mathrm{~s}$

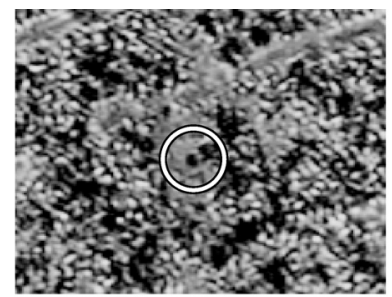

(b) $t=200 \mathrm{~s}$

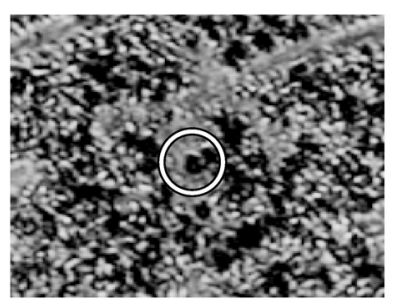

(d) $t=320 \mathrm{~s}$

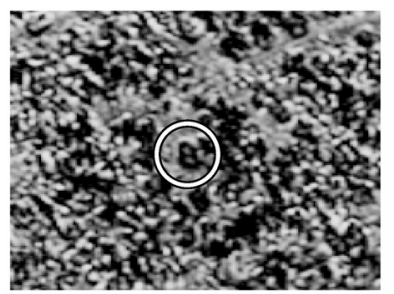

(f) $t=800 \mathrm{~s}$
$50 \mu \mathrm{m}$

Fig. 20. Enlarged view of morphological change on the surface during holding at $600^{\circ} \mathrm{C}$ observed by the laser microscope.

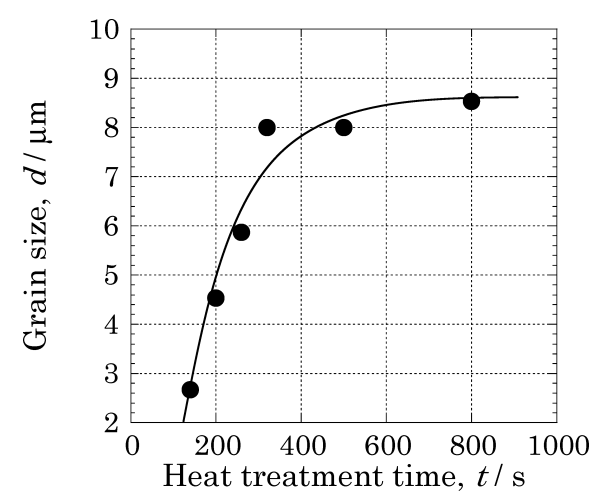

Fig. 21. Relation between heat treatment time and grain size at $600^{\circ} \mathrm{C}$. This heat treatment time includes the heating time from room temperature to $600^{\circ} \mathrm{C}$.

\subsubsection{Relation between $\rho_{\text {grain }}$ and $V_{\text {grain }}$ with Temperature}

Crystallization from glassy state is qualitatively explained on nucleation rate and crystal growth rate as a function of temperature for ordinary glass. ${ }^{16)}$ One example is shown in Fig. 22. The driving force for nucleation increases with decrease of temperature. On the contrary, the mobility of atoms or ions decreases with decrease of temperature. Therefore, the nucleation rate exhibits maximum at a certain temperature. The growth rate also exhibits maximum at a certain temperature in a similar way. The nucleation rate is high and the crystal growth rate is low at relatively low temperature, for example at $T_{1}$ in this figure. On the other hand, the nucleation rate is low and crystal growth rate is high at relatively high temperature, for example at $T_{2}$. Inte- 


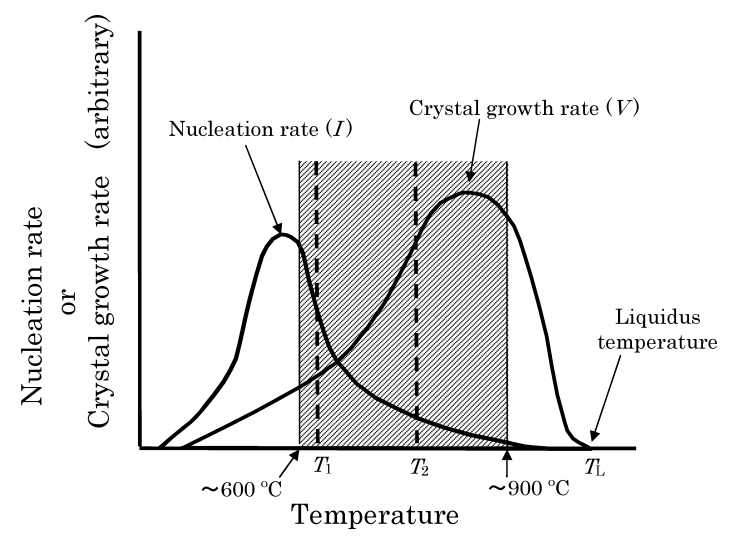

Fig. 22. Schematic curves of the nucleation rate and the crystal growth rate as a function of temperature. Temperature range in this study is also indicated by hatched zone.

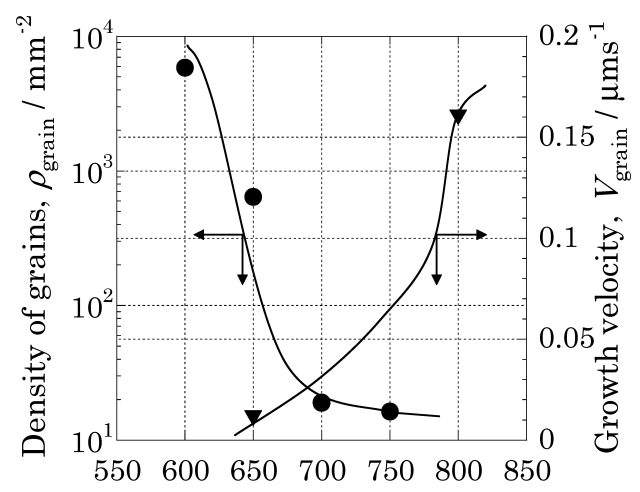

Temperature of heat treatment, $T /{ }^{\circ} \mathrm{C}$

Fig. 23. Relation between $\rho_{\text {grain }}$ and $V_{\text {grain }}$ with temperature of heat treatment. These were the result of interruption tests using the electric furnace.

gration of nucleation rate for a certain period should be the number of grains. Thus, nucleation rate in Fig. 22 directly corresponds to $\rho_{\text {grain }}$ in this study. Crystal growth rate is equal to $V_{\text {grain }}$. Therefore, it is possible to qualitatively compare present experimental results with this figure.

The experimental results on $\rho_{\text {grain }}$ and $V_{\text {grain }}$ as a function of temperature of heat treatment using the electric furnace are shown in Fig. 23. They were discrete data because of the interruption tests. The data points are interpreted with smooth curves. According to this figure, $\rho_{\text {grain }}$ decreases and the $V_{\text {grain }}$ increases with rise of temperature of heat treatment within the range of this study.

In a similar way, the experimental results on $\rho_{\text {grain }}$ and $V_{\text {grain }}$ as a function of temperature of heat treatment on the surface obtained by the laser microscope are shown in Fig. 24. Here again, the data points are interpreted with smooth curves. $\rho_{\text {grain }}$ decreases monotonously with rise of temperature of heat treatment. On the other hand, $V_{\text {grain }}$ increases with rise of temperature and exhibits maximum at around $800^{\circ} \mathrm{C}$. Then, $V_{\text {grain }}$ decreases with rise of temperature of heat treatment.

The experimental results presented in Figs. 23 and 24 are different quantitatively. As mentioned previously, there may be three reasons. The difference of methods of heat treatment, the difference of mobility of ions or atoms and the difference of location for observation may influence the absolute value of $\rho_{\text {grain }}$ and $V_{\text {grain }}$. However, the fashion of

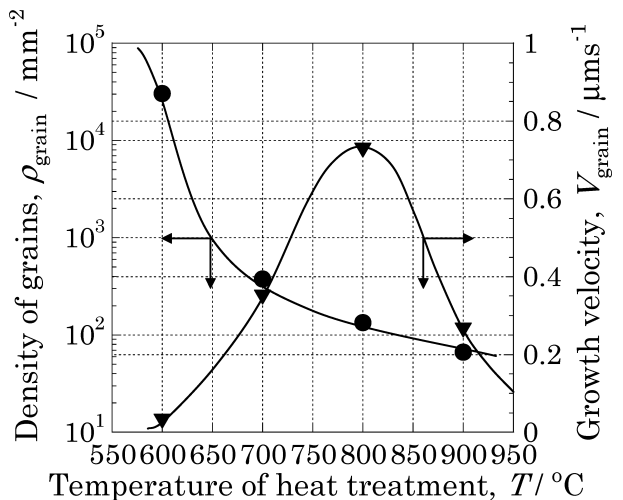

Fig. 24. Relation between $\rho_{\text {grain }}$ and $V_{\text {grain }}$ with temperature of heat treatment. These were the result of in-situ observation using the laser microscope.

change in $\rho_{\text {grain }}$ and $V_{\text {grain }}$ with temperature are quite similar. These experimental results agree with the qualitative representation as shown in Fig. 22. The range of temperature of heat treatment in this study is indicated with hatched zone in Fig. 22. Therefore, it can be concluded that the crystallization of mold flux from the glassy state is similar to that of ordinary glass.

The grain size increased with rise of temperature of heat treatment as shown in Fig. 17. The reason of this is that the number of grains is low due to low nucleation rate at high temperature. Further, high growth velocity also leads to large grain size at high temperature.

The columnar grains were observed when the temperature of heat treatment was relatively high, as shown in Figs. 4(a), 7 and 12. The reason of this is not clear for the moment. However, this may be concerned with nucleation rate as a function of temperature. At high temperature, e.g. $T_{2}$ in Fig. 22, the number of equiaxed grains is low because of low nucleation rate. Therefore, columnar grains which crystallize on the surface can continue to grow without encountering the equiaxed grains.

\subsection{Change of Mold Flux Accompanying Crystalliza- tion}

The results of in-situ observation with the laser confocal microscope indicated that the surface of the specimen at first became smooth and then many waves appeared in a moment as shown in Figs. 8 and 9. The reason that the surface of the specimen became smooth is that the specimen expanded with rise of temperature due to thermal expansion. When the waves appeared on the surface during heating, the specimen was rapidly cooled and XRD analysis was carried out. This confirmed that cuspidine precipitated at this moment. Therefore, it is safely concluded that the shrinkage due to crystallization made the surface of the specimen rough. Furthermore the rate of crystallization of cuspidine is quite high because many waves appeared in a moment.

Formation of wavy surface due to crystallization may lead to mild cooling in the mold as pointed out in the literatures. ${ }^{11,12)}$ 


\section{Conclusions}

To analyze the crystallization process of mold flux from glassy state, a mold flux, which has high tendency for crystallization, has been used in this study. Quenched specimens have been heat-treated in various conditions and characterized. Following conclusions have been derived.

(1) Glassy specimen heat-treated in the electric furnace over $550^{\circ} \mathrm{C}$ for $180 \mathrm{~min}$ crystallized. Cuspidine was confirmed by XRD analysis.

(2) Grains precipitated and grew during heat treatment. Both columnar and equiaxed grains grew dendritically.

(3) The number of grains per unit area $\left(\rho_{\text {grain }}\right)$ and growth velocity of grains $\left(V_{\text {grain }}\right)$ were characterized. $\rho_{\text {grain }}$ decreased with rise of temperature of heat treatment. $V_{\text {grain }}$ increased and decreased after the maximum with rise of temperature. This relationship qualitatively agrees with the theoretical explanation for crystallization of ordinary glass.

(4) In-situ observation carried out with the laser microscope revealed that the glassy specimen crystallized in a moment over $600^{\circ} \mathrm{C}$ and the surface of the specimen turned to be rough. This may lead to mild cooling in the mold.

\section{REFERENCES}

1) C. A. Pinheiro, I. V. Smarasekera and J. K. Brimacombe: Iron Steel- maker, (1994), October, 55.

2) S. Hiraki, M. Kawamoto, T. Murakami, M. Hanao and T. Watanabe: CAMP-ISIJ, 11 (1998), 185.

3) T. Matsumiya, T. Saeki, J. Tanaka and T. Ariyoshi: Tetsu-to-Hagané, 68 (1982), 1782.

4) T. Saeki, S. Ooguchi, S. Mizoguchi, T. Yamamoto, H. Misumi and A. Tsuneoka: Tetsu-to-Hagané, 68 (1982), 1773.

5) Y. Sugitani and M. Nakamura: Tetsu-to-Hagané, 65 (1979), 1702.

6) T. Mizoguchi, N. Ogibayashi and T. Kajitani: Tetsu-to-Hagané, 81 (1995), 971.

7) H. Shimizu, R. Yamaguchi, M. Suzuki, M. Nakada, R. Nishimachi and H. Murakami: CAMP-ISIJ, 9 (1996), 848.

8) A. Yamauchi, S. Itoyama, N. Bessho and K. Sorimachi: CAMP-ISIJ, 8 (1995), 1115.

9) H. Sakai, K. Kawashima, T. Shiomi, H. Okamoto and K. Watanabe: CAMP-ISIJ, 8 (1995), 1015.

10) T. Kanazawa, S. Hiraki, M. Kawamoto, K. Nakai, K. Hamazaki and T. Murakami: Tetsu-to-Hagané, 83 (1997), 701.

11) K. Watanabe, M. Suzuki, K. Murakami, H. Kondo, A. Miyamoto and T. Shiomi: Tetsu-to-Hagané, 83 (1997), 115.

12) A. Yamauchi, K. Sorimachi, T. Sakuraya and T. Fujii: Tetsu-toHagané, 79 (1993), 37.

13) M. Kawamoto, K. Hakari and T. Watanabe: CAMP-ISIJ, 10 (1997), 890.

14) M. Kawamoto, T. Tsukaguchi, N. Nishida, T. Kanazawa and S. Hiraki: ISIJ Int., 37 (1997), 134.

15) W. Kurz and D. J. Fisher: Fundamentals of Solidification, Trans Tech Publication, Aedermannsdorf, Switzerland, (1992), 63.

16) M. Yamane: Hajimete-Glass-Wo-Tukuru-Hito-No-Tameni, Uchida Rokakuho Publishing Company, Tokyo, (1999), 173. 